\title{
TOMÁS NAVARRO TOMÁS, ENTRE DOS CONTINENTES ${ }^{1}$
}

\section{TOMÁS NAVARRO TOMÁS, BETWEEN TWO WORLDS}

\author{
EMILIA CoRTÉS IBÁÑEZ \\ Instituto de Estudios Albacetenses \\ Albacete, JCCM, España \\ eci100@telefonica.net
}

Cómo citar este artículo: Cortés Ibáñez, E. (2020). Tomás Navarro Tomás. Entre dos continentes. Al-Basit (65), 85-112. http://doi.org/10.37927/al-basit.65_3

Recibido/Received: 12-06-2020

Aceptado/Accepted: 10-08-2020

RESUMEN: El exilio, consecuencia de la Guerra Civil española, marcó un antes y un después en muchas vidas, vidas que, en gran medida, tuvieron que reinventarse y que, como ocurrió con las que aquí traemos, nunca volvieron a España. Estados Unidos de América y México son dos de los países que recibieron a gran parte de los intelectuales españoles, como ocurrió con Navarro Tomás y Giménez Siles, respectivamente. Unidos por parentesco familiar, los dos resolvieron sus vidas con la prolongación de sus actividades profesionales: profesor universitario e investigador, y librero y editor; al igual que hicieron algunos de sus amigos -Federico de Onís, Juan Ramón Jiménez- con los que se reencontraron en esos países. Todos ellos salieron con sus familias y tuvieron que adaptarse a un nuevo contexto, a un nuevo estilo de
ABSTRACT: The Spanish Civil War led a lot of people into exile and marked a before and after in their lives, many of whom had to a great extent reinvent themselves and as is the case of those mentioned here never returned to Spain. The United States of America and Mexico were two of the countries that received many of the Spanish intellectuals as was the case of Navarro Tomás and Giménez Siles, respectively. United through blood ties, both of them resolved to carry on their lives pursuing their careers as a university professor and researcher, and a bookseller and publisher; some of their friends, like Federico de Onís and Juan Ramón Jiménez, whom they were reunited with in exile, found a similar solution. All of them left Spain with their families and had to adjust to a new situation, to a new way of life and their grief for Spain. Epis-

\footnotetext{
${ }^{1}$ El presente texto dio lugar a la Conferencia inaugural de la Exposición Tomás Navarro Tomás, cuarenta años sin " $h$ ", dictada en La Roda el 16 de noviembre de 2019, en el Centro Cultural San Sebastián.
} 
vida y a su dolor por España. La escritura epistolar, tan frecuente y socorrida durante el siglo $\mathrm{XX}$, es una fuente inagotable de vivencias, de expresión de sentimientos, de actitud vital: de diferentes facetas de información.

PALABRAS CLAVE: exilio, Universidad de Columbia, México, Navarro Tomás, Rafael Giménez Siles, Federico de Onís, Juan Ramón Jiménez, Zenobia Camprubí, Primera Feria del Libro, Librería de Cristal. tolary writing, so frequent and common during XX Century, is an endless source of life stories, expressions of feelings, attitudes towards life in all its various facets of information.

KEYWORDS: exile, Columbia University, México, Navarro Tomás, Rafael Giménez Siles, Federico de Onís, Juan Ramón Jiménez, Zenobia Camprubí, First Spanish Book Fair, Librería de Cristal.

\section{INTRODUCCIÓN}

No vamos a insistir nuevamente en los primeros tiempos de Navarro Tomás: nacimiento e infancia en La Roda, donde realiza sus primeros estudios; exámenes en el Instituto de Albacete y en el de Alicante; estudios en la Universidad de Valencia y en la Universidad Central de Madrid, donde consigue la licenciatura en Románicas -hoy Filología Hispánica- para a continuación comenzar la tesis de Doctorado, bajo la dirección de su maestro y referente Ramón Menéndez Pidal (Cortés Ibáñez, 2008 y 2014). Es 1906.

En Madrid, la cultura está viviendo nuevos aires. Años atrás, en 1876, un grupo de catedráticos de la Universidad Central de Madrid fue apartado de sus puestos docentes por defender la libertad de cátedra; ante esta circunstancia, estos profesores crearon la Institución Libre de Enseñanza (ILE), una nueva línea de educación, privada y laica, que abarcaba todo el proceso educativo: primaria, secundaria y universitaria.

\section{NAVARRO TOMÁS Y EL CENTRO DE ESTUDIOS HISTÓRICOS}

Comienza 1907, Navarro Tomás acaba de conseguir la licenciatura. La Institución Libre de Enseñanza, teniendo siempre como objetivo primordial la educación, crea la Junta para Ampliación de Estudios (JAE) que hará una labor importantísima en el campo de la enseñanza, y el rodense recibe de dicha Junta una beca o pensión para realizar una investigación del dialecto del Alto Aragón. Poco después, la JAE crea el Centro de Estudios Históricos cuyo objetivo primordial es fomentar 
la investigación científica, guiando, formando, acompañando al investigador desde sus comienzos, y ayudándolo con becas o pensiones en el extranjero que rompan el aislamiento en el que se encuentra la educación en España. La presidencia del Centro recae en el gran filólogo Ramón Menéndez Pidal y la secretaría del mismo en Navarro Tomás. En este mismo año la JAE también funda la Residencia de Estudiantes que, desde sus comienzos y hasta 1936, fue el foco, el referente de la cultura española.

En 1909 Navarro Tomás ingresa por oposición en el Cuerpo de Archiveros, Bibliotecarios y Arqueólogos, es destinado a Ávila y, dos años más tarde, al Archivo Histórico Nacional en Madrid -situado en el edificio de la Biblioteca Nacional-. En 1912, una beca de la JAE lo lleva a Francia, Suiza, Alemania para prepararse científicamente en el campo de la lingüística. A su regreso, ya formado, su jornada laboral se ve ampliada, por la mañana trabaja en el Archivo Histórico Nacional y por la tarde, en el Centro de Estudios Históricos donde funda y dirige el Laboratorio de Fonética Experimental. También se encargará de los Cursos de Lengua Española para extranjeros, que se imparten en la Residencia de Estudiantes, sin olvidar su trabajo en la Revista de Filología Española, fundada en 1914. Al lado de Menéndez Pidal y Navarro Tomás trabaja un grupo de prestigiosos filólogos, entre los que se encuentra Federico de Onís, al que haremos referencia más adelante. Además de todo esto, Navarro continúa realizando trabajos de campo por distintas regiones españolas para recoger material filológico. Unos años después será nombrado director de la Biblioteca del Centro de Estudios Históricos y también da clases de Fonética en la Universidad de Madrid.

Los años 20 fueron fructíferos y de gran proyección para Navarro Tomás. Fue invitado a la Universidad de Puerto Rico y, bajo su iniciativa, se creó el Departamento de Estudios Hispánicos; siguieron distintas universidades norteamericanas -Stanford, Princeton, Columbia, Harvard, Chicago, Indiana, Michigan, etc.- además de las de Caracas y Santo Domingo. En 1930 inició el Archivo de la Palabra compuesto de veinticinco discos en los que recoge las voces de personajes destacados de la cultura española y, en 1931, empieza a organizar todo el material recogido para el Atlas Lingüístico de la Península Ibérica (ALPI), organizado en diez volúmenes y del que es director. Además de todo esto también publica sus trabajos, tanto libros como artículos, estos en prestigiosas revistas internacionales.

Mientras todo esto ocurre a nivel laboral, su vida personal, familiar también sufre cambios. En diciembre de 1914 se casa con la murciana Dolores Guirao Peñalver; en 1916 nace su hija Joaquina y, en 1918, Paquita. Las niñas crecen y se educan en el Instituto Escuela, otra 


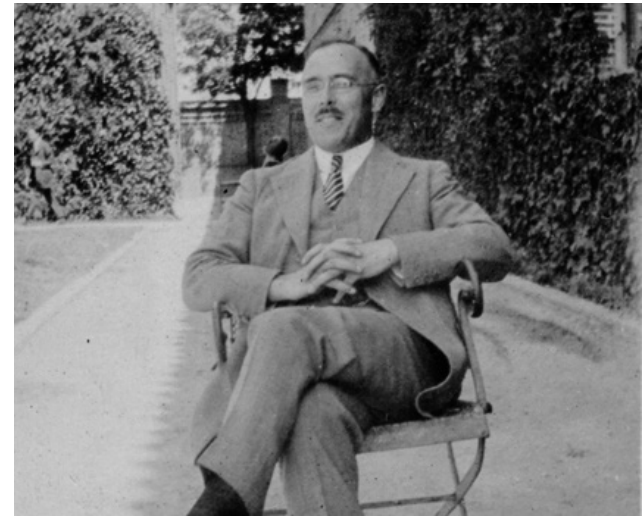

Imagen 0. Tomás Navarro Tomás, en la Residencia de Estudiantes. Madrid

de las aportaciones de la Junta para Ampliación de Estudios. En este Instituto comenzó la reforma educativa de España, y desde aquí se llevaron los nuevos métodos a los centros oficiales. Estaba dirigido por María de Maeztu, contaba con un profesorado de excepción y su objetivo era proporcionar una amplia cultura general, además de desarrollar en el alumno un espíritu abierto; la convivencia profesor-alumno era muy importante y dos innovaciones de este Instituto que resultaron muy llamativas fueron: la coeducación y el carácter voluntario de la enseñanza religiosa.

En 1918 se inicia el ciclo de publicaciones de Navarro Tomás con la aparición, en Madrid, de su tan estudiado Manual de pronunciación española, ciclo que terminará cincuenta y ocho años más tarde, con la aparición de La voz y la entonación en los personajes literarios, en México, en 1976. Entre uno y otro hay alrededor de ciento treinta títulos firmados por el rodense (fonética, fonología, dialectología, geografía lingüística, reseñas, etc.).

Navarro Tomás está perfectamente encajado en el engranaje de la Junta para Ampliación de Estudios, su familia también lo está. Viven en Agustina de Aragón, 11 y, el verano, Dolores y sus dos hijas lo pasan en Arenas de San Pedro, en el valle del Tiétar, provincia de Ávila; él acude a visitarlas antes de que empiecen las clases del Curso de Verano para extranjeros. No ha elegido Arenas de San Pedro de manera casual para el descanso estival, es uno de los lugares preferidos por los miembros de la ILE. En estos años el Centro de Estudios Históricos está trabajando en las campañas de recolección de textos para la sección de folklore y en 1931 Navarro Tomás envía versiones recogidas en Arenas de San Pedro; está claro que no va allí a descansar sino a continuar con su labor. Aquí se encuentra con su amigo Federico de Onís que tiene casa en Arenas donde se refugia los veranos, terminadas sus clases en la Universidad de Columbia de Nueva York, con su mujer y su hijo. Obviamente, ni él ni Navarro se dedican a descansar, solo cambian las clases por los trabajos, por los libros que llevan entre manos. En cierto modo, Arenas es un punto de reunión al que acuden otras personas como Juan Guerrero o Zenobia Camprubí, los dos estrechamente ligados a la acti- 
vidad de innovación cultural que Federico de Onís está realizando en EE.UU.

Arenas de San Pedro tuvo mucha actividad en estos años, colaboró en el tema de la tan necesaria escolarización. Fue sede de las colonias de verano, concretamente, en 1936, el Ayuntamiento de Madrid ofertó trescientas plazas en esta localidad.

En 1933 Navarro Tomás es elegido académico de la Real Academia Española de la Lengua por unanimidad, hecho que él recoge de manera sencilla, en carta a Juan Guerrero el 5 de diciembre de 1933:

Los Sres. Académicos se han portado conmigo muy amablemente. Me han propuesto sin pedirlo yo y me han elegido por unanimidad. Si yo mismo hubiera tenido que solicitarlo y buscar los votos, como otros han tenido que hacer, no hubiera entrado nunca en la Academia. Nunca he trabajado ni he hecho nada con ese propósito. Más bien me parecía que el carácter muy especializado de mis estudios y el apartamiento de toda resonancia popular, en que voluntariamente los realizo, eran motivos para que no se me llamase a la Academia. Me satisface naturalmente que se hayan acordado de mí. (Cortés Ibáñez, 2014, p. 24).

Ingresa en la Academia de la Lengua y ocupa el sillón de la letra "h minúscula"; el discurso de ingreso tiene lugar el 19 de mayo de 1935 y el tema es El acento castellano. Envía el ejemplar firmado a amigos y colegas y recibe felicitaciones y valoraciones muy positivas ${ }^{2}$ : de Cossío (24-5-1935), del ministro de Marina (28-5-1935), de José Lomba (275-1935) y de Emilio Alarcos (29-5-1935) que le escribe desde la Universidad de Valladolid. Fuera del ámbito académico, también recibe la felicitación de Federico Leach que, el 29 de mayo, le escribe desde Barcelona:

[...] y una vez más te felicito de corazón, pues aprecio como el que más el esfuerzo de voluntad que representa llegar a ese elevado puesto por méritos propios, sin influencias políticas. ¿Quién me había de decir que aquel Tomasito que le vi en la bodega de la Cruz hacer sus primeros palotes llegaría a ser uno de los inmortales?

En 1934 Navarro Tomás y Javier Lasso de la Vega (Sevilla, 1892-Madrid, 1990) deciden construir dos viviendas adosadas en la Colonia del Viso, cerca de la Residencia de Estudiantes, uno de los lugares de trabajo de Navarro. En los años veinte Lasso de la Vega fue secretario de la Biblioteca Nacional y, después, director de la Biblioteca

\footnotetext{
${ }^{2}$ Todas las cartas relacionadas con el discurso de ingreso: de Cossío (24-5-1935), del ministro de Marina (28-5-1935), de José Lomba (27-5-1935), de Emilio Alarcos (29-5-1935), de Federico Leach (29-5-1935) y de Navarro Tomás (26-51935) pertenecen a la Biblioteca Histórica, Universidad Complutense de Madrid, Caja BH MSS 303, no 25.
} 
de la Universidad Central y director general de Archivos y Bibliotecas; actualmente es considerado el introductor de las técnicas modernas de documentación en España. Sin duda, los temas de trabajo unían a los dos. Las viviendas estaban en la Colonia de El Viso, manzana XVII, hoteles 4 y 5, calle siguiente a Leizarán. Se trataba de una Cooperativa de casas económicas, según consta en el plano de la vivienda que lleva fecha de 21 de diciembre de 1934, firmado por el arquitecto Rafael Bergamín (Málaga, 1891-Madrid, 1970). ${ }^{3}$ Bergamín ya había construido la Casa del Marqués de Villora -Serrano, 130, Madrid-, la colonia Parque Residencia, el Sanatorio Antituberculoso Los Montalvos (Salamanca), además de colaborar en la Fundación el Amo en la Ciudad Universitaria. Cuando prepara los planos de estas dos viviendas está inmerso en el trabajo de la colonia El Viso (1933-1936). Al llegar la Guerra Civil, sufrió exilio en Venezuela.

Navarro sigue con las mil líneas de su trabajo y, cuando llega julio de 1936, es presidente de la Comisión Gestora del Cuerpo Facultativo de Archivos, Bibliotecas y Museos, secretario de la JAE y director de la Biblioteca Nacional. Estalla la contienda y él protege los fondos de esta institución y algunas bibliotecas de particulares, como lo prueba la carta de Juan Ramón Jiménez:

Ya en La Habana, recibí carta de mi gran amigo Juan Guerrero Ruiz, desde Alicante, diciéndome de parte de Tomás Navarro Tomás, excelente amigo mío también de muchos años y encargado de la Comisión que cuida de proteger bibliotecas, colecciones particulares, etc., si yo quería que se trasladase mi biblioteca y mis manuscritos a Alicante o Valencia. Le puse un cable rogándole que no trasladase nada (Jiménez, 2009, p. 277).

Seguro que, si Juan Ramón hubiese sabido que, en abril de 1939, su casa y su biblioteca serían saqueadas, habría aceptado encantado la protección que le ofrecía.

Navarro también se ocupó de los cuadros del Museo del Prado, parte de los cuales fueron depositados en Valencia, en las Torres de Serranos y en el Colegio del Patriarca, al lado de la Universidad donde estudió sus primeros años de carrera. Su protección también se extiende a un material importante, el $A L P I$, que llevará con él a Nueva York.

\section{NAVARRO TOMÁS SE INSTALA EN VALENCIA}

Tras iniciarse la contienda, el 6 de noviembre de 1936, el Gobierno republicano se traslada a Valencia y se instala en el Hotel Reina Victoria, en la calle Barcas. La Junta de Defensa de Madrid saca de la ciudad a

\footnotetext{
${ }^{3}$ Biblioteca Histórica, Universidad Complutense de Madrid, Caja BH MSS 304, nº 32.
} 
artistas, científicos, escritores e intelectuales y los conduce a la ciudad del Turia; la mayoría de ellos vivirán en la Casa de la Cultura, llamada popularmente "la Casa de los Sabios".

Navarro Tomás también se desplaza a Valencia. Poco a poco llegarán más intelectuales: Juan de la Encina (Ricardo Gutiérrez Abascal) -director del Museo Nacional de Arte Moderno y miembro de la Junta de Incautación y Protección del Tesoro Artístico-, su esposa Pilar de Zubiaurre, Juan José Domenchina, Ricardo de Orueta -director general de Bellas Artes, puesto que dejó en septiembre y fue ocupado por Josep Renau- que también había colaborado en salvar el Patrimonio Artístico, el escultor Victorio Macho, etc. y se alojaron en la Casa de la Cultura, que quedó enclavada en el Hotel Palace, en la burguesa calle de la Paz, 42, de Valencia, convertido en el Ministerio de Asuntos Exteriores de la República. En el hotel se hicieron trabajos de remodelación para su nuevo destino. Albergaba biblioteca, sala de prensa y revistas, Archivo de Guerra y el Centro de Estudios Históricos. También contaba con la cafetería Alianza de Intelectuales. Aquí acudía diariamente Hemingway, cronista de guerra, y desde aquí enviaba sus artículos a los periódicos de Norteamérica.

Una vez terminada la contienda y cerrados el Instituto Escuela, la Residencia de Estudiantes y la Residencia de Señoritas de Madrid, este edificio se dedicó a Residencia. Se aprovecharon los muebles procedentes de la Residencia de Señoritas y hubo dotación de Becas (Calandre Hoenigsfeld, 2018, p.11).

Aquí, en la Casa de la Cultura, no solo vivieron artistas, científicos, escritores, los intelectuales que habían sido evacuados, también los participantes en el II Congreso Internacional de Escritores para la Defensa de la Cultura, inaugurado el 4 de julio de 1937 en el salón de sesiones del Ayuntamiento de Valencia, capital de la República española, y presidido por el presidente del Gobierno Juan Negrín. Fue clausurado por Antonio Machado que leyó el discurso "Sobre la defensa y la difusión de la cultura".

Este Congreso fue organizado por la Alianza Internacional de Escritores Antifascistas, como prueba de solidaridad de los intelectuales con la República española; entre ellos se encontraban Álvarez del Vayo, Benavente, Ricardo Baeza, Margarita Nelken, María Teresa León, Bergamín, Alberti, Navarro Tomás y León Felipe. Además de en Valencia, también se celebraron sesiones de este Congreso en Madrid, Barcelona 


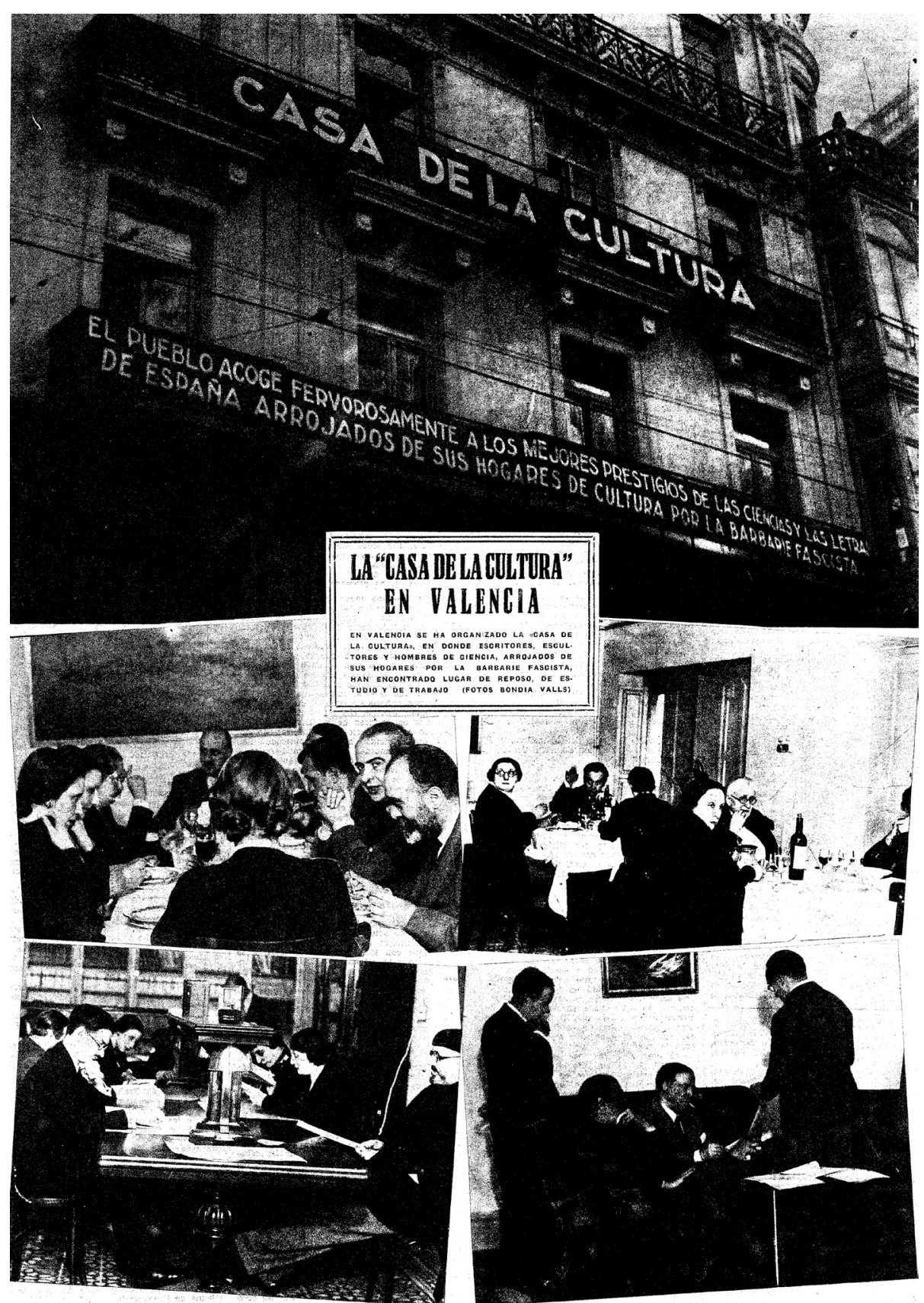

๙ู

Imagen 1.- Casa de la Cultura de Valencia (La Vanguardia, 3-4-1937, p.4) 


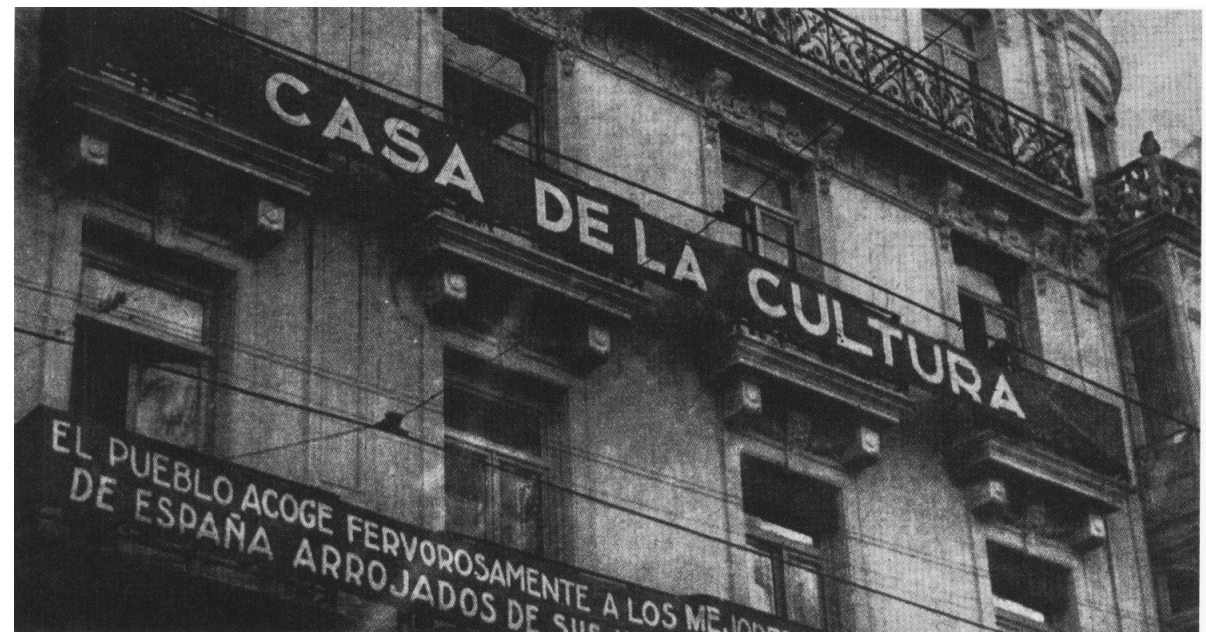

Imagen 2.- Casa de la Cultura de Valencia (La Vanguardia, 3-4-1937, p.4)

y París, con nombres tan conocidos como Rafael Alberti, Louis Aragon, José Bergamín, Bertolt Brecht, Alejo Carpentier, Vicente Huidobro, María Teresa León, Antonio Machado, André Malraux, Pablo Neruda, Octavio Paz, Tristan Tzara y César Vallejo, entre otros.

En estos años, la calle de la Paz era una avenida moderna, iniciada a finales del siglo XIX y conformada por bonitos edificios modernistas que sirvieron como sedes culturales, políticas o sindicales. Era la calle de moda, en ella se encuentran los cafés más modernos: El Siglo o el intelectual Ideal Room, además de almacenes de moda, con ropa prêt à porter, como La isla de Cuba -Plaza de la Reina, 5, chaflán calle de la Paz y calle San Vicente- y El Águila, en Paz 10 y 12. En esta calle se encontraban diferentes sedes: Sede de Mujeres Libres, Sede de la Federación Ibérica de Juventudes Libertarias, Frente de la Juventud -Paz, 30-, Federación Anarquista Ibérica -Paz, 25-, etc. Al final de la calle de la Paz, en la glorieta del Parterre, se encontraba el Ministerio de Marina.

Pilar de Zubiaurre (2009: 285-86), en la entrada de su Diario del 16 de diciembre de 1936, nos muestra el pulso de la ciudad:

Medio Madrid está aquí, muchos son ya viejos en la ciudad; vinieron corriendo cuando aún el enemigo estaba lejos de Madrid y aquí siguen. Valencia parece el reino de Jauja para los que vinimos recientemente de Madrid: los mercados llenos de verduras y frutas, embutidos, quesos, dulce, conservas... Las pastelerías abarrotadas. Los huevos del país son caros -siete pesetas docena-, pero hay más baratos. No nos falta de nada, 


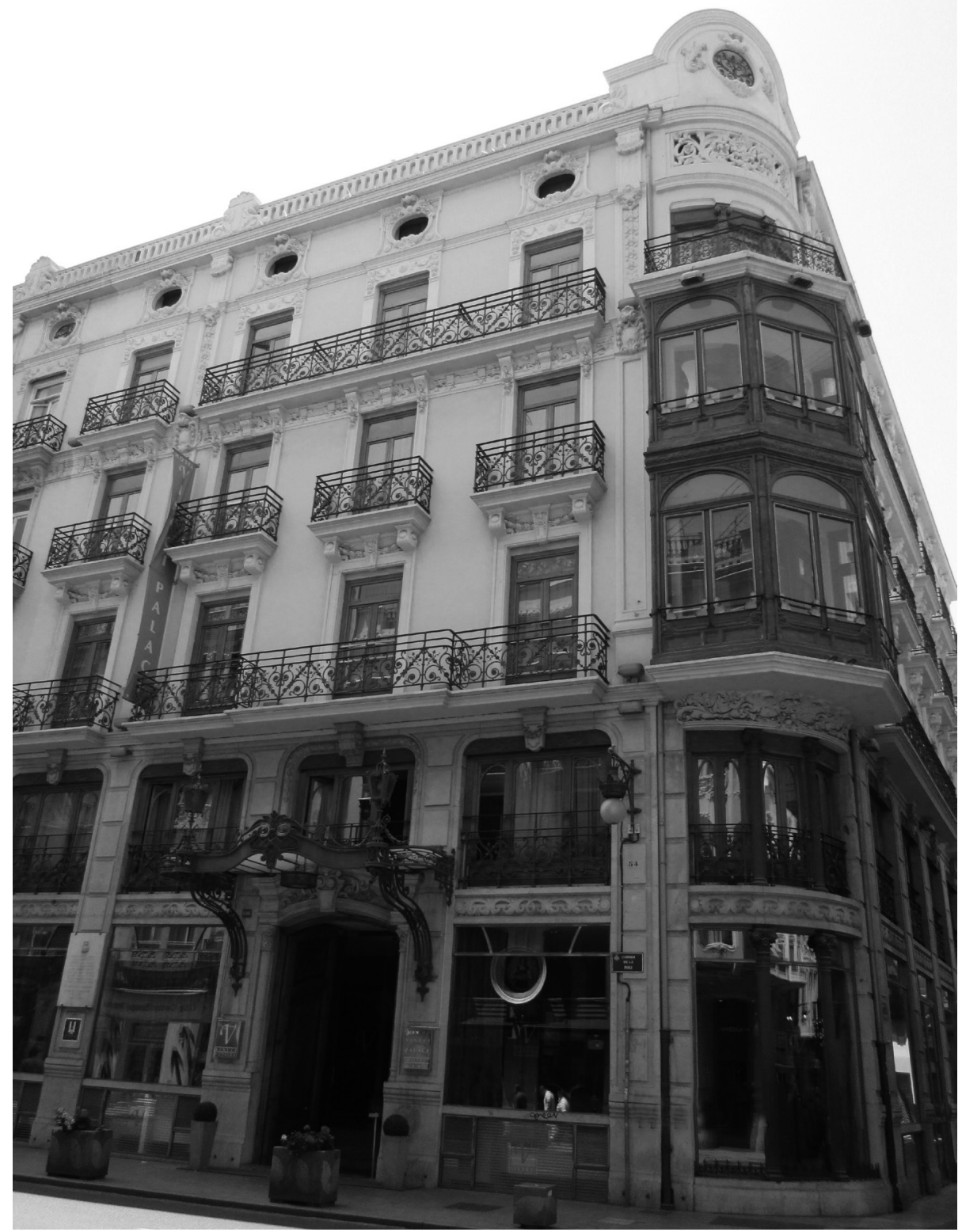

Imagen 3.- Hotel Palace, Calle de la Paz, Valencia

(Archivo privado Emilia Cortés Ibáñez)

solamente la calefacción y, eso sí, en estas casas de países cálidos, en diciembre nos congelamos.

Después de recoger que comieron cocido y que "Estaba deplora- 


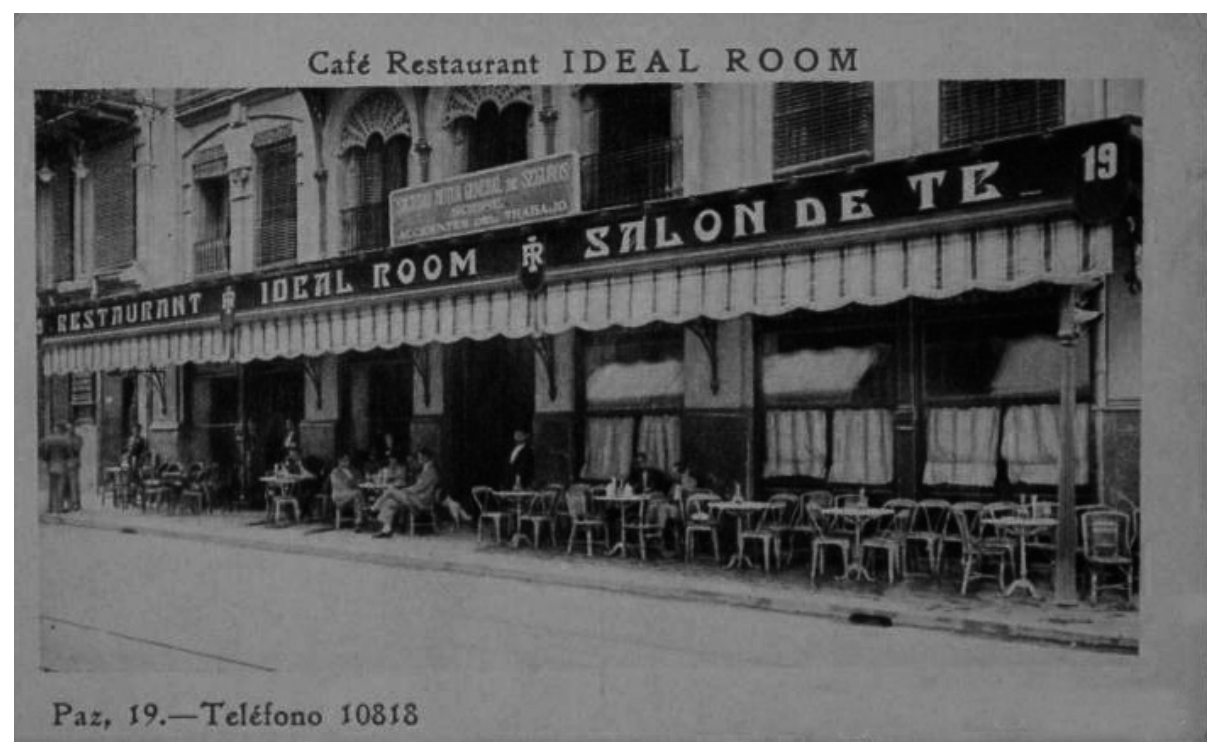

Imagen 4.- Ideal Room, calle de la Paz. Valencia

ble, hecho sin gracia", añade: "En la Casa, desde la visita del Ministro, han mejorado notablemente las condiciones. Hay un poco de calefacción y la comida está mejor" (Zubiaurre, 2009, p. 287).

El Ideal Room acogía entre sus paredes a brigadistas y diplomáticos, corresponsales y espías, también a lo más granado de la intelectualidad: Juan Gil-Albert, León Felipe, Rafael Alberti, Miguel Hernández, Hemingway, John Dos Passos, Francisco Ayala, Antonio Machado, Octavio Paz, Sanchis Guarner -colaborador con Navarro Tomás en el ALPI-, Esteban Salazar, etc., y los artistas Josep Renau, Manuela Ballester y Antonio Ballester. Otro de sus habituales, Max Aub, recuerda este Café: sus veladores de mármol, su suelo blanco y negro, los espejos de sus paredes y su aliviar el calor de los clientes con los helados habituales: horchata, café, mantecado, leche merengada. Precisamente Juan de la Encina también organizó una tertulia en el Café Ideal (González-Allende, 2009, p. 37).

Su mujer, Pilar de Zubiaurre, a propósito de su estancia en Valencia, escribe:

Estamos conviviendo en una casa común, amigablemente, conociéndonos los unos a los otros, realmente sin referencias fantásticas. Cada una de estas personas tiene una misión asignada por el Ministerio que cumplir. Fuera de las horas de trabajo y comida, los cafés, eterno refugio de muchos españoles, son el lugar de reunión (Zubiaurre, 2009, p. 285). 
Para la gestión de la Casa de la Cultura se creó un Patronato dirigido por Antonio Machado e integrado por Manuel Márquez, Navarro Tomás, Victorio Macho y José Moreno Villa.

Los evacuados continuaron llegando, entre ellos Constancia de la Mora, nieta del político conservador Antonio Maura -Jefe de varios Gobiernos durante el reinado de Alfonso XIII-, que trabajaba en la Oficina de Prensa, situada en la Casa de la Cultura, y su marido Ignacio Hidalgo de Cisneros. Ellos se instalaron en el Hotel Ripalda, situado en el Pasaje Ripalda; Hemingway lo hizo en el Hotel Inglés, en la calle Marqués de Dos Aguas.

Navarro, en Valencia, no dio tregua al trabajo. La ciudad estaba viviendo un tiempo de gran actividad cultural dado el gran número de intelectuales que habían sido desplazados; aparecen revistas tan interesantes como Hora de España, Madrid y Cuadernos de la Casa de la Cultura, que contaron con todos estos colaboradores excepcionales de los que disfrutaba la ciudad, entre ellos Navarro Tomás.

En octubre de 1937 Navarro marchó a la URSS, como presidente de una delegación cultural española que asistió en ese país a los actos organizados para conmemorar el vigésimo aniversario de la revolución soviética.

Al mes siguiente, el Gobierno se traslada de Valencia a Barcelona, a la Plaza de Bonanova donde se situó el Ministerio. Llega la temporada de ópera, marzo-abril, en el Liceo, Navarro Tomás está en un palco del proscenio acompañado por Enrique Díez Canedo, asisten a la representación de Sansón y Dalila de Saint Saëns. A mitad de la función se produce un apagón, suenan las sirenas de alarma, explosiones... Navarro Tomás ya muestra desengaño ante la realidad que está viviendo España (Zamora Vicente, 1988, págs. 23-35).

Y la Guerra siguió su curso.

\section{SALIDA AL EXILIO}

El 22 de enero de 1939 el Gobierno español ordenó que todos los organismos oficiales abandonaran Barcelona y el día 26 Navarro Tomás salió hacia la frontera con Francia. Conocemos de su pluma qué ocurrió en esos primeros días, por la carta que, desde Nueva York, 3-31939, escribió al poeta Juan Ramón Jiménez que vivía en Miami. Navarro Tomás le escribe: 
Mi querido amigo.

He tenido una gran alegría al recibir noticias de Ud. por su cuñado Camprubí $^{4}$. Imagino cuánto debe haberle afectado la noticia de la muerte de Machado. Pasamos juntos la frontera de Port-Bou a Cerbére. Corpus Barga y yo pusimos todo nuestro esfuerzo en ayudar a Machado, para hacerle menos dolorosas aquellas horas terribles. No estuvo en campo de concentración. Le dejamos instalado con su madre y su hermano José en el pueblecito de Colliure (Pirineos Orientales). Tan pronto como yo llegué a París, la Embajada de España envió a Machado una cantidad suficiente para hacer frente a los gastos de algunas semanas. Estoy seguro de que no ha muerto de necesidad, ni de abandono, sino del dolor insoportable ante el espectáculo de la ruina y la miseria de España. Hacía tiempo que su salud estaba muy quebrantada. De todos modos su vida hubiera podido prolongarse si no hubiera pasado por tan profundas impresiones. ${ }^{5}$

El grupo con el que cruzó la frontera estaba integrado por los hermanos Machado, la madre de ambos, la esposa de Manuel y sus dos hijas, Carles Riba, Corpus Barga y algunos profesores universitarios de Madrid y Barcelona. Una vez llegados a Cerbère, Navarro continuó a Perpignan para entrevistarse con Álvarez del Vayo, ministro de Estado de la República, que tenía su oficina de manera provisional en esta ciudad, y conseguir que se encargase de los gastos de Machado y familia; siguió a París donde estaba su familia.

Navarro Tomás sale de España y atrás queda todo: su familia, su casa de El Viso -sin haber tenido tiempo de disfrutarla-, su trabajo, su vida... Otra nueva vida empieza. Su esposa, su madre política y sus hijas quedan en París unos meses y, más adelante, embarcarán con destino a México y, al acabar el año, nuevamente se reunirá la familia.

Embarca hacia Nueva York. Allí, en la Universidad de Columbia, se encuentra su amigo Federico de Onís (Salamanca, 1885-Puerto Rico, 1966), miembro del Centro de Estudios Históricos, que en 1916 se había trasladado a dicha universidad, ante el requerimiento hecho por esta institución a la Junta para Ampliación de Estudios; solicitaron un profesor de español, para que organizase la enseñanza de la lengua, la literatura y la civilización españolas, de una manera seria y profunda, como catedrático en el Departamento de Lenguas Romances de dicha

${ }^{4}$ José Camprubí, hermano de Zenobia Camprubí, esposa de Juan Ramón. José es director y propietario del periódico neoyorquino La Prensa (Cortés Ibáñez, 2013).

${ }^{5}$ Carta de Navarro Tomás a Juan Ramón Jiménez, Nueva York, 3-3-1939 (Sala Zenobia-Juan Ramón Jiménez, Universidad de Puerto Rico, Recinto Río Piedras). 
Universidad. La respuesta del Ministerio español de Instrucción Pública fue el envío de Federico de Onís, catedrático de la Universidad de Salamanca y colaborador del Centro de Estudios Históricos. La estancia de Onís en Nueva York, que cuando marchó era para un año, se convirtió en un periodo de treinta y ocho años. La Universidad de Columbia fue su único destino laboral hasta el momento de su jubilación en 1954. Fundó el Instituto de las Españas -1920-, la revista Estudios Hispánicos y la revista Hispánica Moderna. En 1926, apoyado por el rector de la Universidad de Puerto Rico y en colaboración con la Universidad de Columbia y el Centro de Estudios Hispánicos, fundó y dirigió en Puerto Rico el Departamento de Estudios Hispánicos, institución a la que dedicó los últimos años, una vez jubilado de su actividad docente en la Universidad de Columbia.

Onís fue el alma de los estudios hispánicos en América y la persona que recibió y dio trabajo a Navarro Tomás cuando este desembarcó en Nueva York en febrero de 1939 y comenzó su exilio. Para los dos la Universidad de Columbia será su único destino laboral.

Ante el desarrollo de los acontecimientos en España y, antes de que Navarro Tomás llegue a Nueva York, Onís, muy inteligente, muestra al rector de la Universidad de Columbia, Dr. F.D. Fackenthal, razones poderosísimas por las que debe contratar a Navarro como profesor de dicha Universidad:

1) El exilio al que se encuentran abocados muchos intelectuales españoles; si la Universidad de Columbia contrata al menos a uno de ellos, será un ejemplo a seguir por las demás instituciones.

2) A la Universidad de Columbia le interesa elegir la persona más idónea y esa es Navarro Tomás, como lo prueban sus publicaciones; además, es conocido y admirado por los hispanistas norteamericanos, y considerado como el mejor profesor de español. Su presencia en la Universidad de Columbia daría un gran prestigio a la institución.

3) La figura de Navarro Tomás en esta Universidad facilitaría continuar con algunos de los estudios que se estaban llevando a cabo en Madrid, en el Centro de Estudios Históricos. Todo esto ayudaría a las relaciones intelectuales con Hispanoamérica dado que muchos intelectuales españoles ya viven su exilio en esta parte del mundo. Navarro Tomás sería la persona idónea para coordinar trabajo y relaciones entre todos estos países, al ser respetado por ellos.

Onís termina hablando de la honestidad e integridad del filólogo y de lo conveniente que sería que la Universidad de Columbia lo contratara antes de que lo hiciese otra universidad.

La respuesta del rector es rápida, tiene fecha del 31 de enero de 
1939. Invita a Navarro Tomás como profesor visitante con un sueldo de $\$ 7.500$ al año. Su domicilio estará en uno de los edificios del campus de la Universidad, 616 W 116 St, Apt. 62-4, y su oficina, en el edificio del Barnard College de esta Universidad. Al año siguiente, cuando la familia ya esté reunida, vivirán en 535 W 110 St, entre Broadway y Amsterdam Avenue. Esta es una zona en la que muchos españoles se situaron, debido a la proximidad de la Universidad de Columbia -116th St. y Broadway- donde la mayoría de ellos impartieron cursos o conferencias.

Su acogida en el nuevo continente no ha podido ser mejor.

Navarro ha salido de España pero no olvida lo que allí ha quedado. El 3 de marzo escribe a Juan Ramón Jiménez que vive en Miami:

Antes de salir yo de París quedó organizado un Comité de ayuda a los intelectuales españoles, en el que figuran varios de nuestros amigos franceses, entre ellos Jules Romains, Benjamin Cremieux, Marcel Bataillon, Jean Sarrailh y otros. Tenía que ocuparse de sacar a los intelectuales de los campos de concentración, arreglar su situación con la Policía francesa, proporcionarles medios de subsistencia y ayudarles a buscar colocación, donde ganarse la vida. El número de amigos y compañeros que se encuentran sin el menor recurso en el extranjero constituye una enorme empresa para las tareas de este Comité, en las cuales debemos colaborar todos en la mayor medida que alcance nuestro esfuerzo.

Dentro de pocos días se constituirá en Nueva York otro Comité con el mismo objeto, que trabajará en relación con el de París. Sería necesario que en cada país y en cada ciudad importante hubiera un Sub-comité que aportara su esfuerzo a la empresa común. La iniciativa, expresada por U[ste]d en las cuartillas enviadas a [José] Camprubí, es sumamente valiosa. Como U[ste]d se dirige a los españoles y a los hispanoamericanos residentes en los Estados Unidos, nos parece que sería oportuno unir a su firma la de Gabriela Mistral, que nos ha autorizado para ello. Le envío a usted la copia que me ha enviado [José] Camprubí para que U[ste]d mismo pueda modificarla en la forma que considere conveniente. Creo que estará U[ste]d conforme, después de mis noticias, en suprimir la referencia al abandono y a falta de medios materiales que podrían haber causado o contribuido a la muerte de Machado. Las cantidades que se recauden las iremos entregando al Comité Central de París a través de Nueva York.

Disponga U[ste]d de mí en la Universidad de Columbia en donde he empezado ya mi trabajo y presente a Zenobia mis saludos más cordiales (Cortés Ibáñez, 2014, págs.49-50).

La copia a la que se refiere Navarro, que le ha enviado José Camprubí desde el periódico La Prensa, debe de ser la siguiente:

Desde el mes de febrero numerosos intelectuales españoles evacuados del campo de la República, se hallan en Francia faltos de medios de subsistencia y en situación de extrema necesidad. Son pocos los que hasta ahora 
han tenido la fortuna de encontrar en Europa o en América algún refugio acogedor donde reanudar su trabajo.

A medida que pasa el tiempo la situación se hace más angustiosa para los que se ven sin recursos ni apoyo alguno, y especialmente para los que continúan sufriendo hambre y miseria en los campos de concentración del sur de Francia.

Diversas entidades norteamericanas han respondido a la demanda urgente de algunos ilustres escritores franceses a favor de estos artistas, literatos y profesores, a quienes la guerra ha hecho perder el hogar y la posición que en España tenían. Por nuestra parte iniciamos entre los españoles e hispanoamericanos residentes en los Estados Unidos una subscripción a favor de nuestros desventurados amigos y compañeros. No es posible que cada uno de nosotros, con nuestros escasos medios, pueda llegar a todos ni a todo. Rogamos a los hijos de España y de Hispanoamérica residentes en los Estados Unidos que nos ayuden en la medida posible a reunir alguna cantidad con que aliviar la situación de aquellos españoles.

Los envíos pueden verificarse por cheque extendido a nombre del Institute of International Education, Spanish Committee, y remitidos a Professor Tomás Navarro Tomás, 519 Philosophy Hall, Columbia University, New York City.

Cenobia [sic] Camprubí de Jiménez y Juan Ramón Jiménez, Gabriela Mistral, Jorge Mañach, Federico de Onís, Tomás Navarro, Ángel del Río (Jiménez, 2009, págs. 451-52).

Ni Navarro ni Juan Ramón olvidan a sus colegas, los dos están completamente implicados en la ayuda a los intelectuales españoles que, como vemos, se encuentran en situación difícil. Un mes más tarde, el 26 de abril, Navarro nuevamente se dirige al poeta en relación con la ayuda a los intelectuales, lo hace en los siguientes términos:

Querido Juan Ramón,

Ha tenido que extrañarle la falta de noticias nuestras respecto a la subscripción que usted trató de iniciar a favor de los intelectuales españoles. Si no le he escrito antes no ha sido porque hayamos descuidado ni un solo día la realización de esta idea. Era necesario articular esta iniciativa con la actuación de otros grupos de aquí movidos por deseos análogos. Queríamos también asegurarnos del organismo de París encargado de realizar con equidad la distribución de la ayuda que pudiéramos enviar. Todo esto ha ocasionado evidentemente un retraso lamentable, aunque no tanto que hayan desaparecido las ocasiones que requieren nuestro auxilio.

El tiempo transcurrido pide que se introduzca alguna nueva modificación en el llamamiento que usted hizo. Se lo envío antes de distribuirlo para que tenga la bondad de decirme si le parece bien en la forma que ahora lleva o para que lo corrija a su gusto. [...] 
Saludos afectuosos de su buen amigo,

T. Navarro Tomás (Jiménez, 2009, pág. 451). ${ }^{6}$

Y en Nueva York, Navarro Tomás y Juan Ramón se reencuentran. Navarro vive aquí y los Jiménez, aunque se han situado en Miami, pasan temporadas en Nueva York donde vive la familia de Zenobia. El poeta y Navarro se encuentran, incluso comen juntos algunos días, cuando Zenobia está fuera. En esos días, los dos viven su soledad en compañía. La familia de Navarro llegará pronto a México, procedente de París. Los primeros centenares de refugiados españoles, procedentes del sureste francés, llegaron a Veracruz en el buque Sinaia el 13 de junio, ellas lo harán el 14 de septiembre -vía Nueva York- y nuevamente estarán juntos cuando Navarro vaya a México a recogerlas.

Antes de que ellas lleguen a México, Navarro Tomás escribe a Alfonso Reyes -que vive en ese país-, el 11 de septiembre de 1939, lo siguiente:

Dentro de poco recibirá usted la visita de mi familia que va a vivir en México hasta poder arreglar su venida a los Estados Unidos. Si no pudieran venir antes de Navidad, iría yo a verlas para esa fecha. Mi familia está constituida por Dolores, mi mujer; mis hijas Joaquina y Paquita, que usted conoció de niñas, y la madre de mi mujer, anciana de 88 años. Les [sic] he tenido en París hasta que esta tremenda tempestad que empieza a arreciar en Europa ha hecho sacarlas de allí. Embarcaron hace unos días y vienen ahora de camino para México, vía New York. Le agradeceré que les ayude con su buen consejo y amistad (Robb, 1989, p. 606).

Antes de que acabe el año, el 30 de noviembre de 1939, Onís escribe al presidente de la Universidad de Columbia para informarle de toda la labor llevada a cabo por Navarro, y le aconseja que el filólogo pase a ser profesor titular, en lugar de visitante, con el mismo sueldo de \$7.500. ${ }^{7}$ Su vida laboral en Nueva York ya está encauzada dentro de la Universidad de Columbia y será profesor de esta Universidad hasta que se jubile en 1952. Su amistad con Onís y su esposa, obviamente, fue inquebrantable. La amistad que vimos en Arenas de San Pedro ha traspasado fronteras, solo la cortará la muerte de Onís en 1966.

La primera Navidad fuera de España, la de 1939, Navarro Tomás y su familia la pasan en México. Allí fue el filólogo a reunirse con ellas, lo sabemos por la carta, 9 de enero de 1940 (Cortés Ibáñez, 2014, pp. 68-9), que le escribe a Juan Ramón:

\footnotetext{
${ }^{6}$ Carta dirigida a la dirección de la primera de las casas ocupada por los Jiménez en Coral Gables: 728 Second Avenue, S.W., Miami, Florida.

${ }^{7}$ Todas estas cartas (30-1-39, 31-1-39,1-3-39 y 30-11-39), a las que vengo haciendo referencia en relación con el puesto de trabajo de Navarro en la Universidad de Columbia, se encuentran en Columbia University Archives, Central Files 346/18.
} 
Fui a Méjico como tenía pensado a pasar los días de Navidad con mi familia. Ha sido un viaje fatigoso, por tren, vía San Luis-Laredo, de cuatro días de ida y cuatro de vuelta; pero ha sido también fructuoso, pues por fin me he traído aquí a mi mujer y a mi hija Joaquina. Vinimos el día dos y quisimos hospedarnos en casa de las señoras Garmendía Ibáñez ${ }^{8}$ hasta que pusiésemos cuarto independiente. No pudimos quedarnos en casa de dichas señoras porque están levantando precisamente en estos días su instalación para marchar a Puerto Rico. Vivimos en otro piso de la misma casa que las mismas señoras Garmendía nos recomendaron y desayunamos y comemos por los mismos lugares que ustedes conocen.

A diferencia de todas las anteriores, esta es una carta llena de vida, de vivencias, de datos de primera mano, de los vividos en primera persona. En las otras cartas hemos visto al filólogo, en esta vemos al padre de familia, al español, al que, aunque no lo dice, muestra que le duele España:

He visto en Méjico a muchos compatriotas y aunque sólo he estado allí unos cuantos días he recogido una impresión bastante completa de la situación de los españoles. Se advierte fácilmente que su presencia influye poco en la marcha general de la ciudad. La población es tan grande y tan cosmopolita que los españoles pasan en realidad inadvertidos. Muchos de ellos han encontrado trabajo en empresas mejicanas. Las empresas de iniciativa española -editoriales, colegios, academias, restaurantes, pensiones, etc.- van dando empleo a otros muchos. Hay entre ellos rencillas y divisiones que no trascienden al público. Se esperaba que el gobierno mexicano concediese la ciudadanía a los españoles en fecha próxima, cosa que favorecerá principalmente a los obreros para poder sindicarse y celebrar contratos de trabajo.

Enrique Moreno ${ }^{9}$ me envía saludos para usted y me pide su dirección. Sigue de lector en Cambridge. Dice que corre entre los emigrados de Londres y de los demás puntos de Inglaterra la noticia de la aproximación de socialistas y republicanos españoles a los monárquicos para tratar de restablecer la monarquía. Parece que esa misma especie circula también bastante dentro de España. Tal vez es una solución para echar del poder a la falanje [sic], pero no se ve que por ese camino se vaya a dar solución a ninguno de los graves problemas económicos, culturales y políticos que desde hace tanto tiempo vienen perturbando la vida en España.

${ }^{8}$ Las señoras Garmendía eran dos hermanas puertorriqueñas y su tía, las tres solteras, que alquilaban habitaciones. Vivían en el edificio "The Devonshire", 542 W 112 St., cerca de la universidad y acogen en su casa a profesores y estudiantes.

9 Enrique Moreno Báez (Sevilla, 1908-Madrid, 1976), discípulo de Pedro Henríquez Ureña, trabajó en el CEH, profesor en Oxford, Cambridge y Londres; posteriormente, profesor en las Universidades de Oviedo, Santiago de Compostela y Autónoma de Madrid. Es autor de Reflexiones sobre el Quijote, entre otras obras. 
La situación de los españoles en Nueva York sigue siendo la misma que hace unos meses. [...] El pintor Cristóbal Ruiz ${ }^{10}$ tiene decidido marcharse a Méjico. Creo que varios otros tendrán que ir siguiendo tarde o temprano este mismo camino.

María Zambrano fue de Méjico a Cuba a dar unas conferencias y después parece que se trasladaba a Chile donde tienen alguna posibilidad de ocupación ella y su marido. [...] (Cortés Ibáñez, 2014, pp. 68-9).

De las dos hijas de Navarro, la mayor, Joaquina, fue profesora en la prestigiosa universidad privada femenina Smith College, en Northampton, Massachusetts, desde 1943. La menor, Paquita, quedó en México y se casó con Rafael Giménez Siles. Tuvieron dos hijos.

\section{RAFAEL GIMÉNEZ SILES, LIBRERO Y EDITOR}

Rafael Giménez Siles, malagueño de nacimiento (1900), en 1917 se traslada a Madrid para estudiar Farmacia pero su gran pasión fue el libro. Se inició como impresor en el Ministerio de Guerra, mientras realizaba el Servicio Militar, en la Brigada Obrera y Topográfica del estado Mayor que editaba el Anuario Militar de España. Fue librero y editor. En los años veinte, al lado de Joaquín Arderius, tiene su primera imprenta, Argis, con domicilio social en Tarragona, 22, Madrid (Santonja, 1986, pp. 102-103); también su primera editorial, Ediciones Oriente; además, fundó las revistas El estudiante, Nueva España y Post-Guerra, de tendencia progresista.

En febrero de 1928, cuando codirigía la revista Post-Guerra ingresó en la cárcel Modelo de Madrid con una condena de seis meses, por motivos políticos, impuesta por un Consejo de Guerra. Al salir, creó la Editorial Cénit, situada en Concepción Jerónima, 6 y poco después en Lagasca, 55, para terminar en Velázquez, 36 (Santonja, 1983, p. 132). El fondo de Cénit fue gestionado por la Compañía Ibero Americana de Publicaciones (CIAP), relación que terminó en 1931, justo antes de la quiebra de esta gran empresa de los Bauer. A partir de este momento será Espasa Calpe la encargada de la comercialización de Cénit (Santonja, 1983, pp. 132-133). Un balance de las publicaciones que llevó a cabo esta editorial de 1928 a 1936 queda recogido por Santonja (1983, pp. 135-137).

10 Cristóbal Ruiz Pulido (Villacarrillo, Jaén, 1881-Puerto Rico, 1962), pintor, colaboró en la salvación de obras de arte durante la guerra civil. Sufrió exilio en Nueva York y Puerto Rico. 


\subsection{Nace la Feria del Libro de Madrid}

Jiménez Siles fue profesor y editor de la Escuela de Libreros de Madrid, se encargaba de la asignatura "Técnica comercial del libro". Presentó, ante la Cámara Oficial del Libro, un proyecto de Feria del Libro, con la finalidad de acercar el libro al público, que fue rechazado por los libreros y, aunque aceptado por la Sección de editores, no se atrevieron a llevarla a cabo por el tema económico y por la premura de tiempo. Así las cosas, el grupo formado por Ruiz Castillo, Manuel Aguilar, Antonio Sáenz de Jubera y Giménez Siles (Martínez Rus, 2003, p. 225) propuso la celebración de la primera Feria del Libro de Madrid, del 23 al 29 de abril de 1933, en el Paseo de Recoletos. Fue inaugurada por el presidente del Consejo de Ministros, Manuel Azaña, y por Fernando de los Ríos, ministro de Instrucción Pública. Acudieron veinte editoriales madrileñas, los stands fueron decorados por el polaco Mariano Rawicz, tipógrafo, diseñador gráfico y director artístico de la Editorial Cénit, creada por Giménez Siles.

El resultado de la Feria fue muy positivo tanto por la asistencia de público como por las ventas que hubo; fue un acontecimiento cultural. Giménez Siles dirigió la Feria del Libro de 1933 a 1935, además de colaborar en las Ferias del Libro de distintas ciudades españolas.
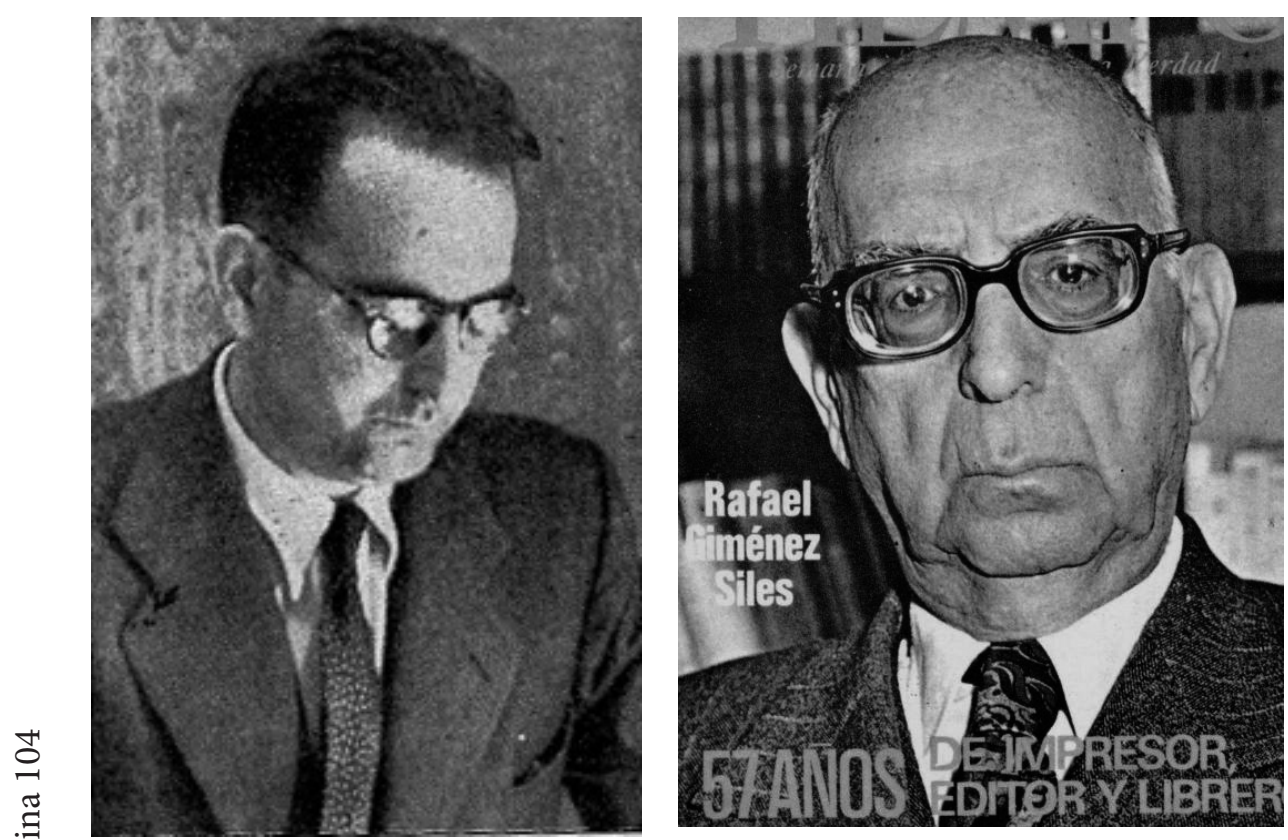

Imágenes 5a y 5b. Rafael Giménez Siles 


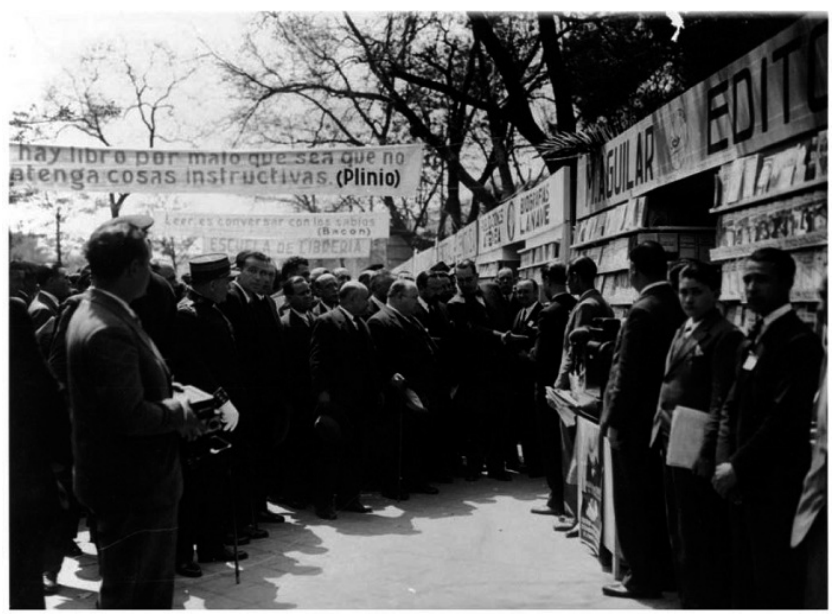

Imagen 6. Primera Feria del Libro, Paseo de Recoletos, Madrid, 2329 de abril de 1933

Al mismo tiempo impulsó un nuevo proyecto: los camiones-stand, diseñados por su amigo Arturo Ruiz-Castillo -hijo del editor José Ruiz-Castillo-, equivalente a lo que hoy conocemos por bibliobuses. Contenían dos toneladas de libros, tenían instalación de altavoces, radio, micrófono, cine, tocadiscos, etc. y recorrían los pueblos acercando los libros al ciudadano. Durante el día había música y por la noche se proyectaban películas en la pantalla frontal, cedidas por el Patronato de Misiones. La función de estos camiones terminó en 1936 cuando fueron requisados por el V Regimiento y enviados al frente de la Sierra de Guadarrama. La labor que llevaron a cabo está en la línea de las actividades de las Misiones Pedagógicas, de las que Giménez Siles era vocal. Además de toda esta actividad siguió creando editoriales y distribuidoras.

\subsection{El exilio}

En 1936, en Barcelona, Giménez Siles entró en contacto con el Embajador de México en España, Alberto Tejada, y con el secretario de la Embajada, quienes estaban interesados en la labor que Giménez Siles venía haciendo por el libro español y deseaban hiciese algo similar por el libro mexicano. Le propusieron que viajase a México pero él continuó con su labor en España. En 1937 organizó la representación editorial de España en la Exposición Internacional de París y montó el Curso Superior de Encuadernación, de mucha tradición en España (Lago Carballo y Gómez Villegas, 2006, pp.218-26).

En 1939 marchó al exilio, previa estancia en el campo de concentración/refugiados de Argelès-sur-Mer, en los Pirineos Orientales, próximo a Colliure, en condiciones inhumanas. En este mismo campo 
estuvo Josep Renau, posiblemente coincidieron. Robert Capa, corresponsal gráfico de guerra, lo describe como:

[...] un infierno sobre la arena: los hombres allí sobreviven bajo tiendas de fortuna y chozas de paja que ofrecen una miserable protección contra la arena y el viento. Para coronar todo ello, no hay agua potable, sino el agua salobre extraída de agujeros cavados en la arena (Todos los rostros, 2008).

Su amistad con el Embajador de México lo sacó del campo de concentración y marchó a este país, donde organizó su vida.

Giménez Siles llegó a México un poco antes que las mujeres de la familia Navarro, lo hizo el 25 de mayo de 1939. El inicio fue difícil pero rápidamente entró en contacto con escritores e intelectuales. Tres meses antes, el 7 de julio de 1940, al lado de Martín Luis Guzmán, funda la Edición y Distribución Iberoamericana de Publicaciones (EDIAPSA), que se ocupaba de la edición y distribución de publicaciones en toda Hispanoamérica; además de libros, editaba revistas. El 15 de octubre de 1940 se nacionalizó mexicano.

\subsection{Librerías de Cristal}

En el año 1904, se había iniciado en la ciudad de México -Avenida Cinco de Mayo- la construcción del Teatro Palacio de Bellas Artes que no se inauguraría hasta 1934. No lejos del Teatro se levantó una pérgola para hacer representaciones al aire libre. Esta pérgola estaba formada por dos filas de columnas, paralelas, que seguían un trazado ondulado y sustentaban un techo; elemento arquitectónico que genera un corredor semiabierto y, adornado con plantas trepadoras, marcaba el paso de un espacio abierto a uno cerrado.

Y en esta pérgola, cerrada con cristaleras y con un piso añadido, en 1940 Ediapsa abre la primera Librería de Cristal, dentro de una línea fuertemente innovadora -exposiciones de pintura, conferencias, café, tertulias literarias, horario: 8-24 horas-; era lugar de reunión de los intelectuales de la época. La adaptación corrió a cargo del arquitecto Arturo Sáenz y el resultado dio alrededor de cuarenta metros de escaparate. Tuvo gran éxito, fue la primera librería de autoservicio. En la planta superior estaba el Café donde se celebraban tertulias literarias con destacados escritores.

Giménez Siles fue director de la empresa durante más de cuarenta años y siguió creando numerosas empresas editoriales. Impulsó la Primera feria del Libro de México, inaugurada el 2 de diciembre de 1947 (Gil, 2019). En 1973 la Librería de Cristal fue destruida para construir la estación de metro Bellas Artes.

En 1975, cuando la librería tenía dieciocho sucursales en la capital y once en provincias, Giménez Siles se jubila y en 1976 vende las libre- 


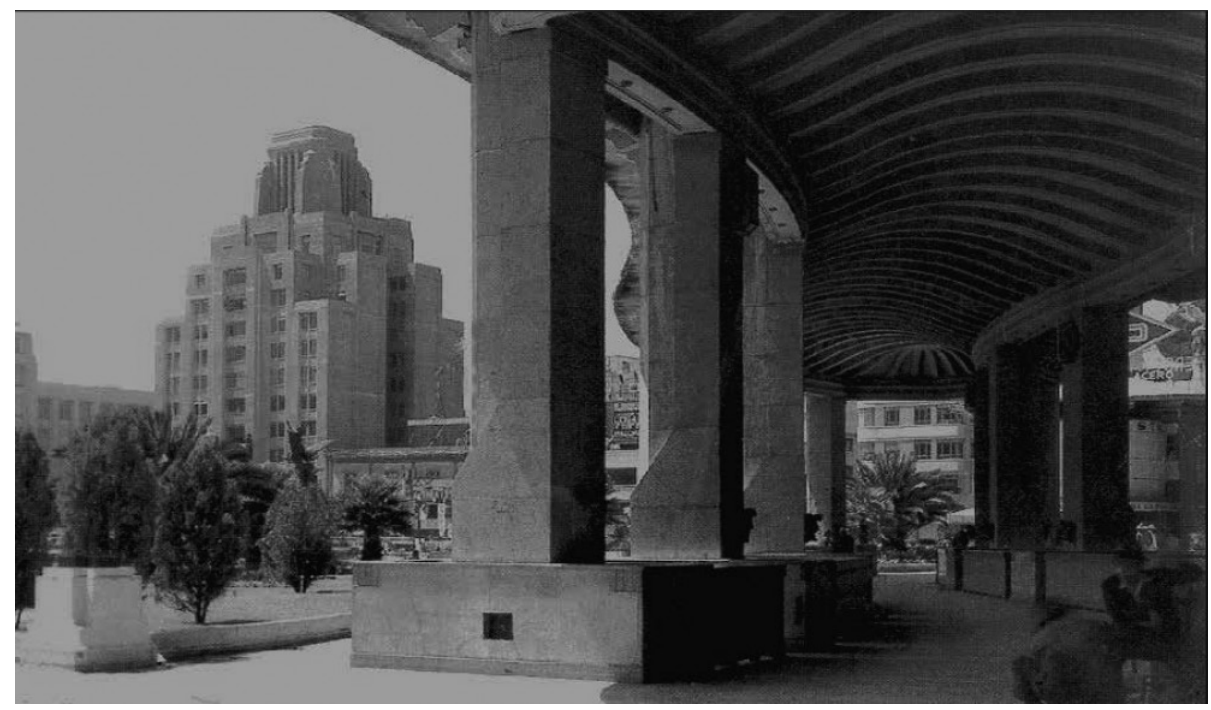

Imagen 7. Pérgola, México.

rías. El 10 de abril de 1992 la razón social deja de ser Ediapsa y pasa a ser Librerías de Cristal, S.A. de C.V. En 2004 la cadena llega a tener setenta y tres sucursales (Pereira, 2004).

De 1973 a 1982, la dirección de la empresa recayó en uno de sus hijos, Rafael Giménez Navarro que, en 1980 trajo a Madrid el proyecto de las Librerías de Cristal. Con tal objeto consiguió un local idóneo al

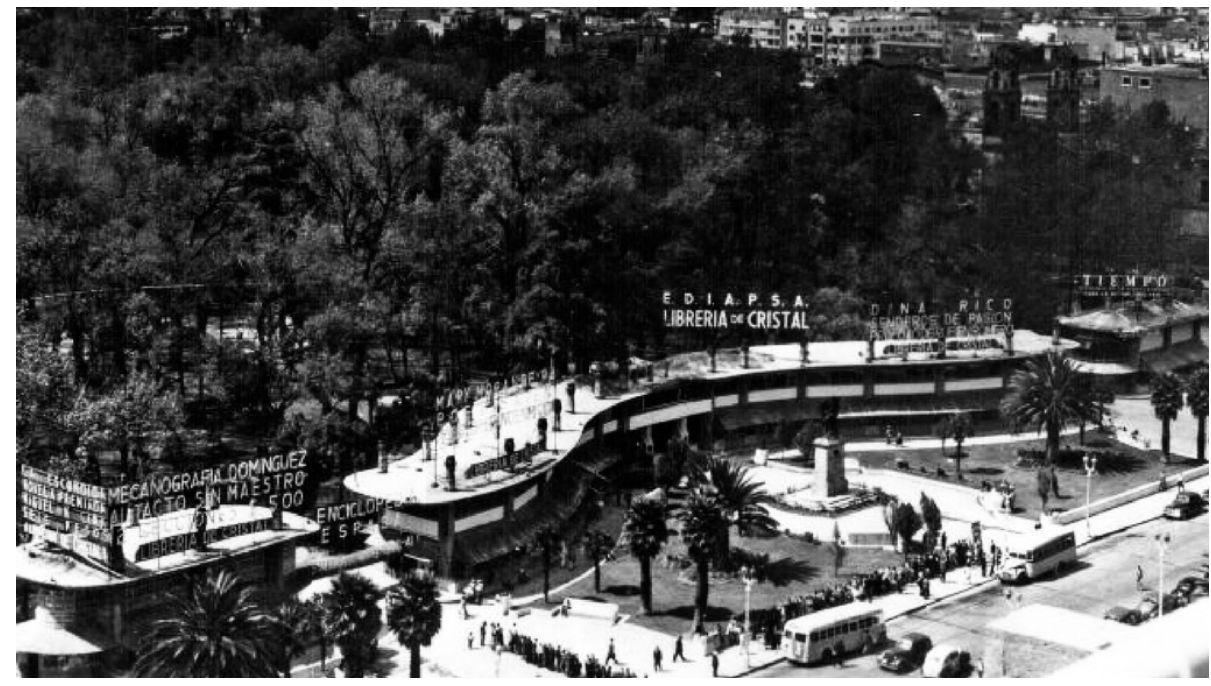

Imagen 8. Librería de Cristal, México. 


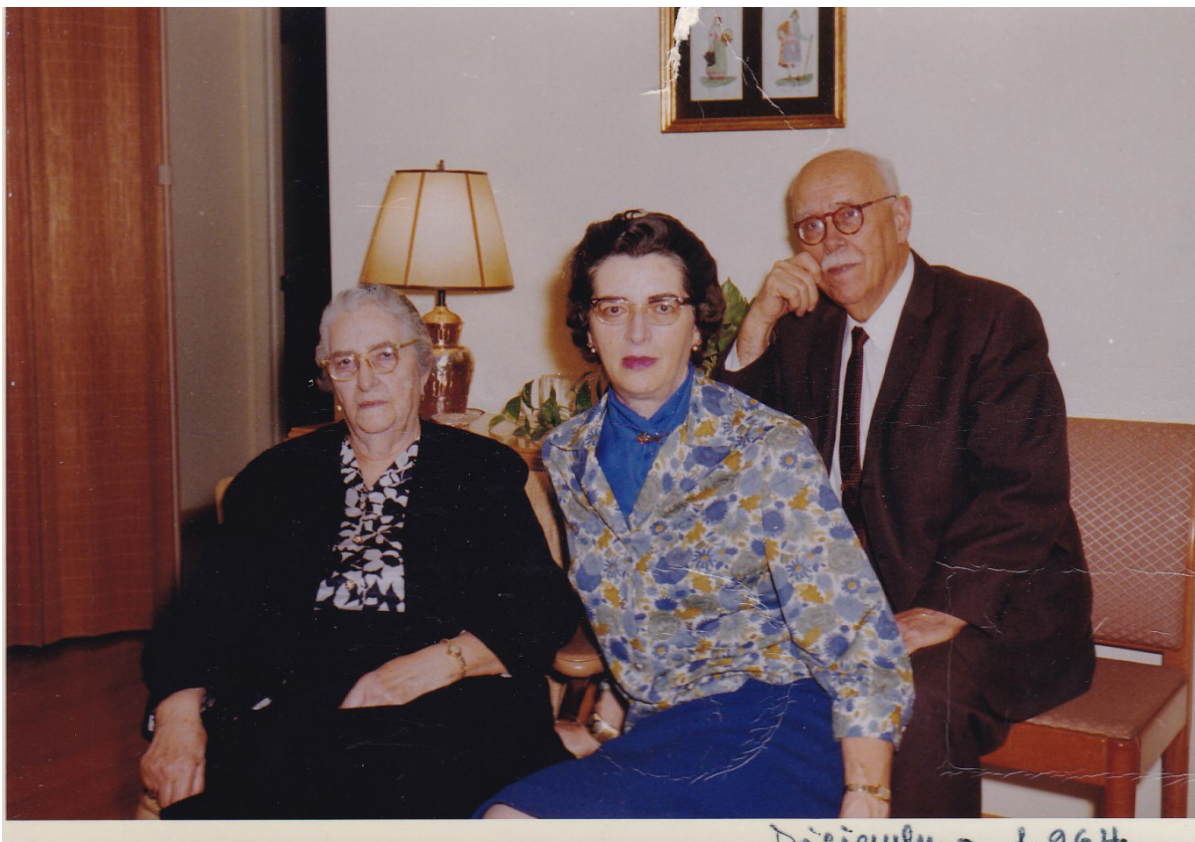

Imagen 9. El matrimonio Navarro y Paquita (Archivo privado Roque Navarro Moraté)

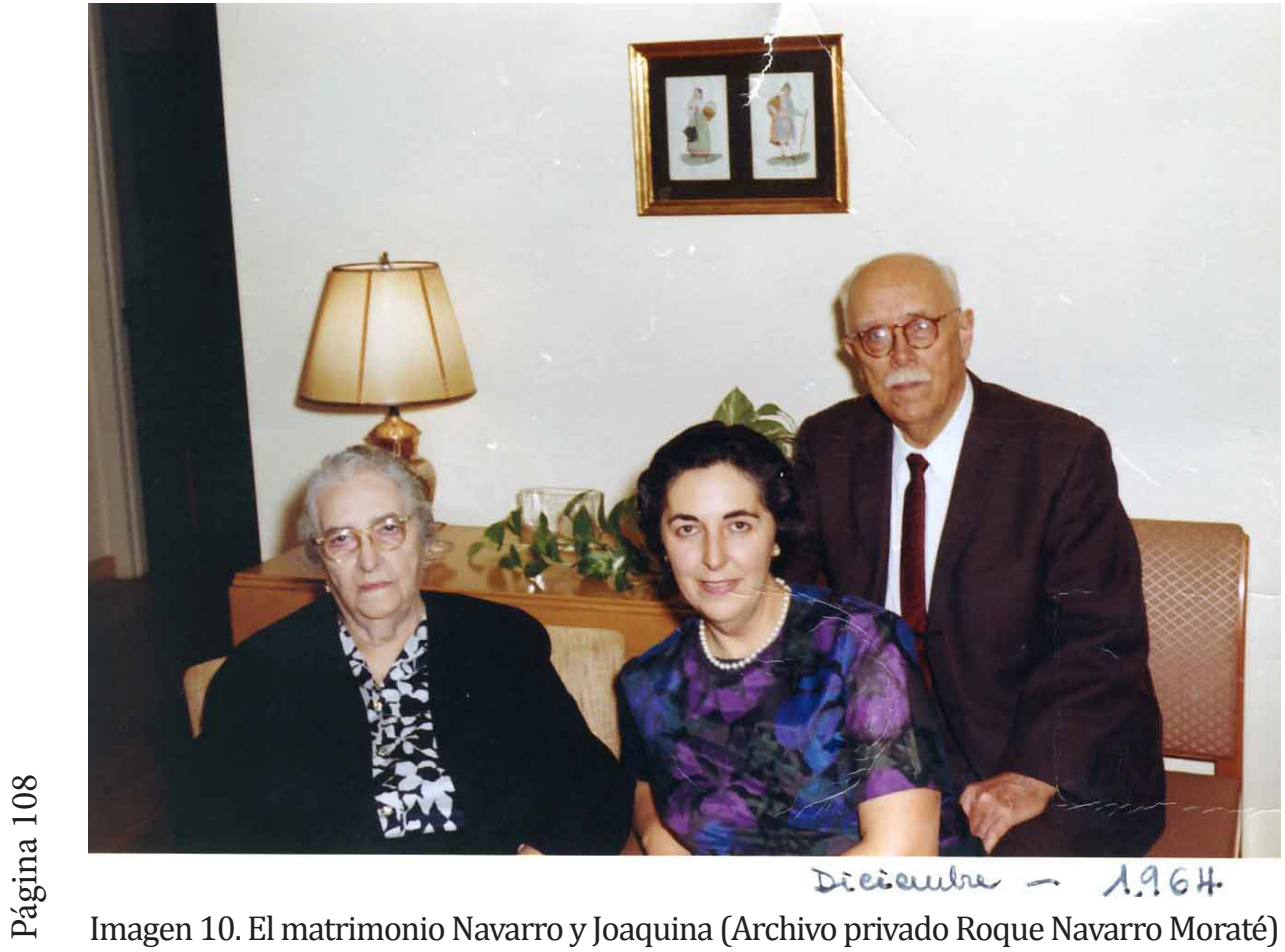


lado de la Puerta de Alcalá (G.P.C., 1980), el proyecto incluía establecerse también en Barcelona pero, al parecer, la idea no prosperó.

Paquita Navarro murió en México en agosto de 1984 y Rafael Giménez, en su obra Retazos de vida de un obstinado aprendiz de editor, librero e impresor (1984), escribió como dedicatoria: "En memoria de Francisca Navarro, mi entrañable esposa, inestimable colaboradora que me alentó durante cuarenta y cinco años de exilio".

Rafael murió en México en 1991.

\section{ETAPA FINAL}

Navarro Tomás se jubiló donde empezó su trabajo norteamericano, en la Universidad de Columbia, en 1952. Él y Dolores siguieron unos años en Nueva York y en 1957 se marchan a Northampton, al lado de su hija Joaquina, profesora del Smith College. Y en esta ciudad recibió a alumnos y amigos, como Alonso Zamora Vicente y Maㅡ Josefa Canellada, que venían a visitarlo; a sus familiares españoles que, después del homenaje que se le hizo en La Roda en 1974, le trajeron un libro de oro que recogía las firmas de sus paisanos.

Navarro y Dolores murieron en Northampton en 1979 y 1985, respectivamente. Joaquina murió en la residencia Nathaniel Witherell Nursing Home, en Greenwich, Connecticut, en febrero de 2017, a los 100 años.

En 1974 el Instituto de Estudios Albacetenses nombró a Tomás Navarro Tomás miembro de honor y la Biblioteca del centro lleva su nombre: Biblioteca Tomás Navarro Tomás. En 2007, el filólogo recibió la Medalla de Oro de Castilla-La Mancha.

Cerramos esta aproximación a Navarro Tomás con las palabras de Rafael Lapesa (1980, p. 3), su alumno y amigo:

Infundía a la vez respeto y confianza. Hablaba reposadamente, con voz grave y sonora [...]. Su dicción perfecta no era artificial [...]. Sus palabras eran dignas y comedidas [...], sus juicios ponderados. Sin embargo, en el varón prudente había también un hombre resuelto; una vez tomada una decisión, la llevaba hasta sus últimas consecuencias. Tuvo firmeza de roble; se mantuvo fiel a sus convicciones y a la línea de conducta que se había trazado, sin debilidades ni condescendencias. En 1939 salió de España [...]. No volvió a pesar de su intensa nostalgia [...].

Vida llena, cumplida, [...]. Si hubiera vivido en el siglo XV, Hernando del Pulgar lo habría llamado "hombre esencial" [...], "hombre verdadero y constante." 


\section{REFERENCIAS BIBLIOGRÁFICAS}

AZNAR SOLER, M. (2007). Valencia, capital literaria y cultural de la república (1935-1937). Valencia: Publicacions de la Universitat de València.

CALANDRE HOENIGSFELD, C. (2018). La Junta para la Ampliación de Estudios republicana frentepopulista, represaliada por el franquismo y olvidada por la transición y la democracia, Historia Actual On Line, 16, primavera, pp.7-16.

CASTILLO DURÁN, F. del (2011). Antonio Machado en el II Congreso de Intelectuales Antifascistas: faltándole el respeto a la divinidad, Revista HMiC, IX, pp. 71-91. http://webs2002.uab.es/hmic

CAUDET, F. (1974). Presentación de Hora de España nº 23, AIH. Actas V., pp. 279-285. http://cvc.cervantes.es/literatura/aih/pdf/05/ aih_05_1_025.pdf

CORTÉS IBÁÑ̃EZ, E. (2008). Cartas familiares de Tomás Navarro Tomás: la infancia revivida. Al-Basit, Monográfico dedicado a Tomás Navarro Tomás, 51-52, año XXXII. Albacete: Instituto de Estudios Albacetenses, pp. 115-180.

CORTÉS IBÁÑEZ, E. (2013). José Campubrí y La Prensa, pilar del Hispanismo en Nueva York. Oceánide 5. http://oceanide.netne.net

CORTÉS IBÁÑEZ, E. (2014). Cartas de Navarro Tomás a Juan Ramón Jiménez y Juan Guerrero (1917-1950). Cuadernos Albacetenses 18. Albacete: Instituto de Estudios Albacetenses.

DESVOIS, J.-M. (2005). Las ferias del libro y la prensa de Madrid bajo la II República, en Prensa, impresos, lectura en el mundo hispánico contemporáneo: homenaje a Jean-François Botrel, Desvois (ed.). Université Michel de Montaigne Bordeaus 3: PILAR, pp. 283-296.

GIL, M. (2019). “Una vida de libro”, https://antinomiaslibro.wordpress.com/2019/01/21/una-vida-de-libro/

GIMÉNEZ SILES, R. (1980). Testamento profesional. Comentarios, ilustraciones y sugerencias al finalizar la tarea editorial, librera e impresora. México: ed. del autor.

GIMENEZ SILES, R. (1984). Retazos de vida de un obstinado aprendiz de editor, librero e impresor. México: Ediapsa.

GONZÁLEZ-ALLENDE, I. (2009). Pilar de Zubiaurre: de la modernidad a la evocación, en P. de Zubiaurre, Evocaciones. Artículos y diario (1909-1958), Edición e Introducción Iker González-Allende. Donostia: Saturrarán, pp. 13-109.

G.P.C. (1980). Librería de Cristal para Madrid, Cisneros, Madrid, 28 de noviembre, p. 10.

JIMÉNEZ, J.R. (2009). Guerra en España, prosa y verso (1936-1954), ed. 
de Á. Crespo revisada y ampliada por S. González Ródenas. Huelva: Point de Lunettes.

LAGO CARBALLO, A. y GÓMEZ VILLEGAS, N. (eds.) (2006). Un viaje de ida y vuelta. La edición española e iberoamericana (1936-1975). Madrid, Ediciones Siruela.

LAPESA, R. (1980). Navarro Tomás. Vida y obra de un noble varón. Ínsula, no 395, enero, Madrid, p. 3.

MARTÍNEZ RUS, A. (2003). La política del libro y las ferias del libro de Madrid (1901-1936), Cuadernos de Historia Contemporánea, no 25, pp. 217-234.

PEREIRA, A. (ed.) (2004). Diccionario de literatura mexicana. Siglo XX. México: Universidad Nacional Autónoma de México, Editorial Coyoacán, $2^{\text {a }}$ ed., pp.143-145.

ROBB, J. W. (1989). Alfonso Reyes, Tomás Navarro Tomás y el Centro de Estudios Históricos, NRFH, XXXVII, 2, pp. 603-620.

SALABERRÍA, R. (ed.) (2007). Tomás Navarro Tomás: ciudadano TNT. Toledo: Consejería de Cultura.

SANTONJA, G. (1983). Breve perfil de la Editorial Cénit (Madrid, 19281936), pp.129-139, Cervantes Virtual.

SANTONJA, G. (1986). Del lápiz rojo al lápiz libre. La censura de prensa y el mundo del libro. Barcelona: Anthropos.

TAPIA BOLÍVAR, D. (1982). Recuerdo de la aventura humana y editorial de Rafael Giménez Siles, El País, 9 de junio.

Todos los rostros. Los campos de concentración franceses (2008). Lugar de la memoria visual de los prisioneros y presos republicanos y antifranquistas, 5 de agosto, http://todoslosrostros.blogspot. com/2008/08/los-campos-de-concentracin-franceses.html

Tomás Navarro Tomás (1884-1979). (1988). La Roda (Albacete): Edición patrocinada por Excma. Diputación de Albacete y Excmo. Ayuntamiento de La Roda.

ZAMORA VICENTE, A. (1988). Tomás Navarro Tomás (1884-1979). En Tomás Navarro Tomás (1884-1979), La Roda: Diputación de Albacete-Ayuntamiento de La Roda, pp. 23-35.

ZUBIAURRE, P. de (2009). Evocaciones. Artículos y diario (1909-1958), Edición e Introducción Iker González Allende. Donostia: Saturrarán. 


\section{ARCHIVOS CONSULTADOS}

ARCHIVO HISTÓRICO NACIONAL, Madrid.

BIBLIOTECA HISTÓRICA. UNIVERSIDAD COMPLUTENSE. Madrid.

COLUMBIA UNIVERSITY ARCHIVES, CENTRAL FILES, New York.

SALA ZENOBIA-JUAN RAMÓN JIMÉNEZ. Universidad de Puerto Rico, Recinto Río Piedras. 